\title{
Deprivation payments
}

\author{
Still awaiting change
}

Deprivation payments were introduced with the 1990 general practitioner contract with the intention of putting more resources into practices where deprivation might be expected to increase the demand for services. ${ }^{1}$ Laudable though the aim might be, the results have been much criticised. Arguments over using the "Jarman index"' to assess demand for services and the method of payment have obscured the principle underlying the payments. ${ }^{3-7}$

This was that a proportion of the pool funding for General Medical Services would be redirected to practices in high demand, deprived areas. Using scores derived from the Jarman underprivileged area index for this purpose seems to have face validity - the index was developed from a survey of one in 10 British general practitioners who were asked to weight social factors according to how much they thought they increased workload. Using census data, scores were derived for areas of the country either on the basis of ward or enumerator district (with average populations of 5327 and 450 respectively) and extra money is provided to practices with a higher proportion of factors perceived by a representative sample of doctors to equate to high patient demand.

Critics have argued that no evidence exists that Jarman's weighted factors actually create extra workload; indeed, some state that doctors in high scoring areas may actually work fewer hours. ${ }^{8}$ Such arguments are themselves spurious since general practitioners are able to ration their workload despite potential demand ${ }^{9}$ by controlling access through measures such as rapid consultations, short surgery hours, or other barriers to visits. They can thereby create patient expectation of the level of demand that will be serviced.

The actual workload of doctors does not necessarily reflect accurately the potential demand for their services, as unmet need is not taken into account. Calculating any extra resource using an index based on doctors' own perceptions of what creates work seems the more valid approach as these will presumably be factors deterring doctors from working in underprivileged areas or causing them to limit access so as to avoid overwork.

Despite almost a decade of critical review and the existence of alternative formulas for identifying deprivation ${ }^{10}$ the Jarman index remains as good an indicator of potential demand for general practitioner services as exists. Major problems, however, arise over its application. Census data are used to calculate the scores, but these may be as much as 12 years out of date (current data were collected in 1981; scores based on the 1991 census are expected later this year).

Averaging scores to a ward can exclude payments to practices in deprived parts of otherwise affluent wards and put unnecessary resources into practices in pleasant parts of underprivileged wards. Graduating payments and particularly the high score needed to trigger any payment are problems. Most important is this extra income might not result in any attempt to improve care.

The Department of Health has talked about refining elements of the general practitioner contract. Basing the deprivation payments on the Jarman index still seems the best option, although it is time the Department of Health supported research into its validation. Such studies should focus on the workload in comparable practices - for example, practices in high and low deprivation areas with similar levels of commitment.
Considerable fine tuning of the eligibility criteria is needed. Payments could be limited to a maximum number of patients per general practitioner which would stop the protests that a single handed general practitioner with a list of 3000 in an area of high deprivation receives an extra $£ 28800$ a year without any obligation to provide extra services. That maximum should be as low as 1300 to 1500 patients per full time principal. Perhaps the most important function of deprivation payments was to compensate practices with low lists after the introduction of the new contract, which linked income much more closely to capitation. The payments should not encourage high lists in areas of deprivation.

Eligibility according to ward is a further problem that using enumeration districts would partially overcome, although a much greater margin of error (approaching 50\%) comes from converting patient postcodes to enumeration districts than to wards. Perhaps some of the total expenditure on deprivation payments could be reserved by the family health services authorities for appeals, providing that the money was "ring fenced."

Authorities could, within clear guidelines, make discretionary payments - for example, to practices on the boundaries of "deprived" wards who could show that they would receive payment if enumeration districts were used. Similarly, practices could appeal if they had evidence that the population characteristics had altered substantially since the last census. Furthermore, it could be possible to update locally certain factors in the Jarman index more regularly, especially unemployment rates, which change so rapidly.

Lowering of the entry point for payment from the 30 point on the Jarman scale-Jarman has suggested that 16 is more appropriate ${ }^{5}$-and the use of more payment bands might be considered. This would increase the proportion of patients attracting some deprivation payment to their practice from the current $9 \%$ to about $20 \%$ of the population. Current total spending on deprivation payments could be maintained despite increasing the eligibility for payments if the average per capita fee was lowered. Spreading the benefits too thinly, however, might undermine the viability of the most needy practices.

An important priority is to ensure that extra income is spent on extra activity. Limiting maximum eligible patients per doctor would help, as would requiring some broad declaration by the practice as to how the sum would be spent (such as will occur with the revised health promotion payments). Practices receiving substantial payments should be expected to employ sufficient ancillary staff-for example, nearer two full time equivalent staff per doctor rather than the one to one ratio so often seen. Pressure could also be exerted on practices to adopt 10 minute consultation bookings, given the relation between length of consultation and quality of performance. ${ }^{11}$ It is, however, difficult to see how ambitious practice aims could be realised from payments made and therefore subject to change on a quarterly basis.

We need to canvas opinion and collect data from innovative practices in deprived areas to find out how payments have been best used to support their greater patient demand. Clearly without the deprivation payments some good inner city practices would have been bankrupted by the new contract. Unfortunately, because of anomalies in the system, 
the needs of other deserving practices are still not being met.

RICHARD HOBBS Professor

Department of General Practice,

University of Birmingham,

Birmingham B15 2TT

1 Health Departments of Great Britain. General practice in the National Health Service: the 1990 contract. London: HMSO, 1989.
2 Jarman B. Identification of underprivileged areas. $B M \mathcal{F}^{1983 ; 286: 1705-9}$

Hutchinson A, Foy C, Sandhu B. Comparison of two scores for allocating resources to doctors in deprived areas. BMF 1989;299:1142-4.

4 Smith GD. Second thoughts on the Jarman index. BMF 1991;302:359-60.

5 Talbot RJ. Underprivileged areas and health care planning: implications of use of Jarman indicators of urban deprivation. $B M \mathcal{F}$ 1991;302:383-6.

6 Car-Hill RA, Sheldon T. Designing a deprivation payment for general practitioners: the UPA ( 8 ) wonderland. BMf 1991;302:393-6.

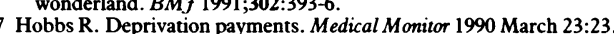

8 Wilkin D, Hodkin P, Metcalf D. Factors affecting workload: is received wisdom true? In: The medical annual. Bristol: John Wright, 1986:185-96.

Leavey R, Wood J. Does the underprivileged area index work? BMF 1985;291:709-11.

10 Balarajan R, Yuen P, Machin D. Deprivation and general practitioner workload. BM 1992;304:529-33.

11 Howie JGR, Porter AMD, Forbes JF. Quality and use of time in general practice: widening the discussion. BMF 1989;298:1008-10.

\section{Improving London's health service}

\section{Now comes the hard part}

After a century's diagnosis of the ills of London's health service many in Britain will welcome almost any prescription that stops $15 \%$ of the population consuming $20 \%$ of NHS resources. But for those living and working in London the decisions made last week by the government (see $\mathrm{p} 537)^{1}$ have to face a harder test. Will they improve or worsen the standard of care given to Londoners - and to a wider group of patients who use London's specialist services and benefit from its research and teaching?

Many people have been disappointed that last week's decisions were not more precise-defining, for example, exactly what should happen to St Bartholomew's or Charing Cross Hospital. But London's pattern of hospitals is such a historical muddle that no one can wave a wand and transform everything overnight. Restructuring will inevitably entail compromises, and it is important that those who have to make the compromises work should be involved in fashioning them. In general Mrs Bottomley has set clear boundaries and timetables for the decisions and told the relevant authorities to work out their own salvation within them. In return she should ensure that her mechanisms for protecting research and education are robust enough to enable London's hospitals to operate fairly within the internal market.

The boundaries make sense, but there is an air of indecent haste about the timetables. Even though many of Sir Bernard Tomlinson's recommendations, now endorsed by the government, worked with the grain of changes already occurring, ${ }^{2}$ some of the timetables are short. The specialty reviews, for example, have to assess current and projected needs, define criteria for tertiary services, and advise on the most cost effective and clinically effective locations - all by the end of May. This work will not be done in a vacuum, ${ }^{3-5}$ but for a problem that has existed for at least a lifetime a few more months of thought might lead to better outcomes, and ones that will be more readily accepted.

Likewise, the agent of change might have been better devised to give more confidence in the outcome. At present the London Implementation Group smells too much of hole in the corner deals: the working part of the group consists only of two named people, one of them a former Thames regional chairman, and the ordinary members of the specialty review committees (see p 589) and of the all important Primary Health Care Forum had not yet been announced as we went to press. The group might knock heads together but it doesn't seem designed to do the equally important job of explaining what is happening to staff and patients. And Londoners need explanations and reassurance. Over the past few months they have been told that their primary and community health care is awful; now the government tells them that accident and emergency departments will shut, along with 2000-odd hospital beds, when their immediate evidence is that it is hard to get into hospital. Likewise, the implementation group's human resources subgroup sounds too low key to convince staff that the NHS will tackle the problems of maintaining morale and preserving skills while changes go on. ${ }^{6}$

Part of the problem for Londoners is that the notion of transformed primary and community care, breaking down the boundaries between hospital and community, is still unclear. The government has accepted Tomlinson's recommendation for investment in premises and has set up an initiative zone to encourage new ideas. There are plenty of good ideas around, ${ }^{7-10}$ but the worry is that the sheer difficulty of practising in inner cities will overwhelm even the most enthusiastic practitioners and managers ${ }^{10}$ and that they will "settle for more of the same ... but out of better buildings." Much will depend on the leadership and vision of the Primary Health Care Forum.

Perhaps the biggest gap in both the Tomlinson report and Making London Better concerns research and postgraduate teaching. The government has already decided to bring special health authorities into the internal market. It also wants a market in research, and it promises a mechanism for funding the excess costs of academic teaching and clinical research. But there is little inkling of how the mechanism will work, and we have to wait until December for the management executive and the Department of Education to come up with ideas. They are badly needed: as Green has said, "It would be easy for clinical research to become the first and indeed the greatest casualty of reductions in size in London." This is particularly true since London has a pressing need for a shift in acute beds towards those serving elderly Londoners with multiple diseases and away from younger patients with interesting single diseases (J James, MSD Foundation symposium, 1992). ${ }^{12}$ London may just be carrying too big a burden of research and teaching for its population - but the means by which research and education get redistributed, rather than simply shut, remain unclear.

It is easy to criticise the government's decisions: after a century of inertia, making changes in London was always going to be difficult, and Mrs Bottomley deserves credit for getting the process started. But she needs to remember that deciding strategies is easy; implementing them is hard. She has given a lot of commitment to the strategy; she now needs to give as much to the process of change and to ensuring that the public understands it.

Londoners have for long been perversely proud of a health 